\title{
THERIA_G: a software program to numerically model prograde garnet growth
}

\author{
F. Gaidies $\cdot$ C. de Capitani $\cdot$ R. Abart
}

Received: 27 March 2007/ Accepted: 31 October 2007/Published online: 30 November 2007

(c) Springer-Verlag 2007

\begin{abstract}
We present the software program THERIA_G, which allows for numerical simulation of garnet growth in a given volume of rock along any pressure-temperaturetime $(P-T-t)$ path. THERIA_G assumes thermodynamic equilibrium between the garnet rim and the rock matrix during growth and accounts for component fractionation associated with garnet formation as well as for intracrystalline diffusion within garnet. In addition, THERIA_G keeps track of changes in the equilibrium phase relations, which occur during garnet growth along the specified $P-T-$ $t$ trajectory. This is accomplished by the combination of two major modules: a Gibbs free energy minimization routine is used to calculate equilibrium phase relations including the volume and composition of successive garnet growth increments as $P$ and $T$ and the effective bulk rock
\end{abstract}

Electronic supplementary material The online version of this article (doi:10.1007/s00410-007-0263-z) contains supplementary material, which is available to authorized users.

Communicated by J. Hoefs.

THERIA_G is coded in Fortran77. For the computer code as well as for the executable files see the Electronic supplementary material.

F. Gaidies - C. de Capitani

Department of Geosciences, University of Basel,

Bernoullistrasse 30, 4056 Basel, Switzerland

R. Abart

Institute of Geological Sciences, Free University Berlin,

Malteserstrasse 74-100, 12249 Berlin, Germany

F. Gaidies ( $\square)$

Department of Geoscience, University of Calgary,

Calgary, AB, Canada T2N 1N4

e-mail: fgaidies@ucalgary.ca composition change. With the second module intragranular multi-component diffusion is modelled for spherical garnet geometry. THERIA_G allows to simulate the formation of an entire garnet population, the nucleation and growth history of which is specified via the garnet crystal size frequency distribution. Garnet growth simulations with THERIA_G produce compositional profiles for the garnet porphyroblasts of each size class of a population and full information on equilibrium phase assemblages for any point along the specified $P-T-t$ trajectory. The results of garnet growth simulation can be used to infer the $P-T-t$ path of metamorphism from the chemical zoning of garnet porphyroblasts. With a hypothetical example of garnet growth in a pelitic rock we demonstrate that it is essential for the interpretation of the chemical zoning of garnet to account for the combined effects of the thermodynamic conditions of garnet growth, the nucleation history and intracrystalline diffusion.

Keywords Equilibrium thermodynamics .

Chemical fractionation - Intragranular diffusion .

Growth kinetics · CSD · THERIAK

\section{Introduction}

The chemical-zoning patterns of garnet porphyroblasts play a key role in reconstructing the pressure-temperature $(P-T)$ history of metamorphic rocks (e.g. Spear 1993). Due to the comparatively slow rates of cation diffusion in garnet (e.g Loomis 1982; Chakraborty and Ganguly 1992), garnet compositional zoning, which reflects parts of the $P-T-t$ evolution of the rock, may be preserved over geological time spans even at medium- to high-grade metamorphic conditions. 
To extract geothermobarometric information from garnet composition, numerical models, which simulate the influence of changing $P-T$ conditions on garnet composition during growth, can be employed (e.g. Cygan and Lasaga 1982; Loomis 1982, 1986; Loomis and Nimick 1982; Spear et al. 1991a). In combination with petrographic, geochemical, and microstructural investigations, this approach may provide essential information on the metamorphic evolution of the garnet-bearing rock sample.

The DiffGibbs computer program (Florence and Spear 1991; Spear and Florence 1992; Spear et al. 1991b) was one of the first numerical models, which was designed to predict the chemical-zoning pattern of garnet that grows in equilibrium with a given set of phases along a specific $P-T-t$ path. The DiffGibbs program accounts for chemical fractionation during garnet growth as well as for intragranular diffusion in garnet. DiffGibbs modelling requires knowledge of the compositions and modal abundance of all phases that pertain to the equilibrium assemblage in a given rock sample at specified $P-T$ conditions. It does not test for the stability of this assemblage and, as a consequence, does not update phase relations along the $P-T-t$ trajectory. In addition, the DiffGibbs model does not allow for simulation of formation of an entire garnet population, i.e. in DiffGibbs modelling all garnet crystals nucleate at the same time, so that the influence of the nucleation history on the chemical zoning of garnet cannot be addressed adequately.

In this communication, we present the THERIA_G software program. Similar to DiffGibbs, it simulates garnet growth and accounts for chemical fractionation due to the formation of garnet, intracrystalline diffusion within garnet and diffusional fluxes between garnet porphyroblasts and the matrix. However, THERIA_G implements the THERIAK code (de Capitani and Brown 1987), which is based on Gibbs free energy minimisation. Therefore, the configuration of the thermodynamically stable metamorphic mineral assemblages as well as the chemical compositions and modal abundances of all phases that evolve as the external conditions and bulk rock composition change during garnet growth, can be taken into account.

In addition, THERIA_G allows to simulate the formation of an entire garnet population, which comprises several classes of garnet individuals, i.e. porphyroblasts of different size that nucleate and start to grow at different times along the $P-T-t$ trajectory. If component diffusion in the matrix is fast, i.e. not rate limiting, the final sizes of the garnet individuals reflect their time of nucleation. THERIA_G can be used to simulate the formation of garnet crystals of progressively smaller size so that any prescribed rock-specific crystal size frequency distributions (CSD) can be reproduced. This offers the possibility to evaluate the influences of the growth history of garnet on its chemical zoning pattern.
The aim of the current communication is to describe the software program in detail and to discuss an application of THERIA_G to the average garnet-bearing metapelite of Shaw (1956) using different scenarios for garnet growth kinetics and $P-T-t$ trajectories. Applications to polymetamorphic garnet-bearing metapelites from the Austroalpine basement are presented in a companion paper (Gaidies et al. 2007).

\section{Simulation of garnet growth}

The THERIA_G program consists of two major parts: (1) THERIAK (de Capitani and Brown 1987) computes the equilibrium phase relations for given $P$ and $T$ conditions and a specific effective bulk rock composition ${ }^{1}$ using an internally consistent thermodynamic database (e.g. Berman 1988; Holland and Powell 1998). This allows to predict the amount and composition of garnet that is formed after an incremental change in $P$ and $T$. The calculated amount of garnet is added by THERIA_G to pre-existing garnet porphyroblasts as successive spherical shells. In general, for such calculations, thermodynamic equilibrium is assumed to be maintained between the garnet rims and the rock matrix at any time during garnet growth. (2) The diffusion module calculates the effects of intracrystalline multicomponent diffusional transport between successive garnet shells, the initial compositions of which represent garnet growth zoning. Furthermore, the diffusion module calculates the component fluxes between garnet and the matrix.

The two basic components of THERIA_G communicate via an interface, which is also used for data input. The input parameters comprise the initial thermodynamically relevant bulk rock composition, the $P-T-t$ trajectory over which garnet growth is to be modelled as well as the relative garnet CSD of the respective garnet population. In addition, the thickness of successive garnet shells needs to be chosen. Finally, the thermodynamic database and the kinetic parameters for intragranular diffusion in garnet need to be specified.

As the thermodynamically relevant composition, the bulk rock composition of an unaltered rock volume of hand specimen size that is devoid of macroscopically detectable compositional heterogeneity may be chosen. For THERIA_G modelling it is essential to choose a $P-T-t$ path, which begins outside the garnet stability field. For practical purposes it is expedient to first delineate the garnet stability

\footnotetext{
${ }^{1}$ We refer to the composition of the volume domain in a rock over which thermodynamic equilibrium is established during each increment of garnet growth as the "thermodynamically relevant" or "effective bulk rock composition".
} 
field by constructing an equilibrium assemblage diagram. This can be done by using the program DOMINO, which is part of the THERIAK-DOMINO software package (de Capitani 1994) and is available online at: http://titan. minpet.unibas.ch/minpet/theriak/theruser.html.

The different individuals of a garnet population are assigned to radius classes via the CSD, which gives the relative abundance of garnet individuals of a specified size range. An example of a relative CSD is illustrated in Fig. 1.

THERIA_G simulates garnet growth as a succession of spherical shells. The resolution of growth increments is determined by the choice of a fixed thickness $\Delta r_{\text {shell }}$, for the successive garnet shells. For each growth increment, $\Delta r_{\text {shell }}$ and the CSD data are used to calculate the volume of garnet, which is searched for along the pre-defined $P-T-t$ path. That is, if $P$ and $T$ are incremented within the garnet stability field, THERIA_G varies $P$ and $T$ along the prescribed $P-T$ trajectory until the volume of newly formed garnet is such that it may be distributed to form spherical shells of thickness $\Delta r_{\text {shell }}$ on all garnet individuals and, if applicable to newly formed garnets of size $2 \Delta r_{\text {shell }}$. For conditions outside the garnet stability field, $P$ and $T$ are incremented along the $P-T$ path with regular steps of at least $0.5^{\circ} \mathrm{C}$ or 20 bar. For conditions within the garnet stability field, this procedure yields irregular $P-T$ steps that largely depend on the chosen shell thickness and, in general, increase with garnet growth. In contrast, the thickness of successive garnet shells is constant. This technique is motivated by the fact that the regular spacing of successive garnet shells renders interpolation methods during diffusion modelling unnecessary. Such interpolation would have been indispensable to keep numerical errors small, if the successive garnet shells were irregularly spaced (see below).

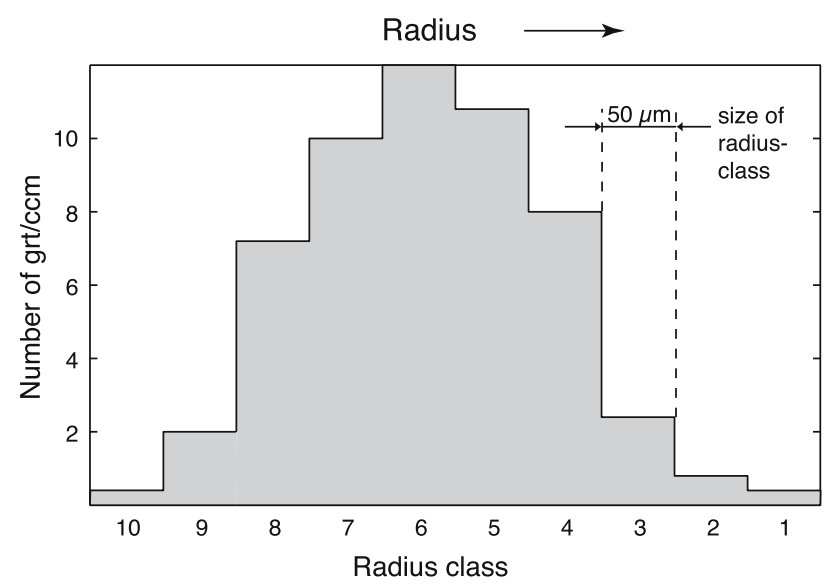

Fig. 1 Relative garnet crystal size frequency distribution (CSD1) used for garnet growth simulations
The choice of $\Delta r_{\text {shell }}$ is guided by finding a compromise between computational efficiency, which is highest for large values of $\Delta r_{\text {shell }}$ and high accuracy, which requires small $\Delta r_{\text {shell }}$. The calculation of chemical fractionation associated with garnet growth is particularly sensitive to the choice of $\Delta r_{\text {shell. }}$. It turned out that a $\Delta r_{\text {shell }}<10 \mu \mathrm{m}$ ensures satisfactory accuracy when modelling the formation of a garnet population where the largest individuals have a diameter of $2 \mathrm{~mm}$.

The present version of THERIA_G offers calculations with the dataset of Holland and Powell (1998) (thermodynamic database of THERMOCALC, version 3.21). For the kinetic parameters, the data acquired by Chakraborty and Ganguly (1992) or Loomis et al. (1985) may be chosen.

\section{Modelling of garnet fractionation}

When the given $P-T-t$ path intersects the garnet stability field for the first time in a simulation, THERIA_G calculates the initial garnet volume from the thickness of the first shell and the CSD information, i.e. number of garnet individuals per unit volume of the rock that pertain to the first radius class of the specified CSD. It starts to iteratively search for the $P-T$ conditions along the given $P-T-t$ trajectory, at which the corresponding garnet volume is grown. The solution is accepted, as soon as the differences in $T$ and $P$ after successive iteration loops is smaller than $10^{-4 \circ} \mathrm{C}$ or $20 \mathrm{bar}$, respectively. As a result, the initial garnet growth increment is formed, which has uniform chemical composition.

To account for chemical fractionation during garnet growth, the material, which is used to produce garnet, is numerically removed from the bulk rock composition. In general, this leads to chemical fractionation. The new effective composition of the matrix is then used for the next garnet volume search. In contrast to isothermal fractionation models (Atherton 1968; Hollister 1966), this approach accounts for the progressive modification of the distribution coefficients with $T$ and $P$. If the steps in $P$ and $T$ become infinitesimally small, our model approaches Raleigh fractionation.

During the search for the $P-T$ increment, which is needed to create the next garnet shell, the program keeps track of changes in the equilibrium assemblage. If a phase disappears from the garnet-bearing assemblage or a new phase comes in before the $P-T$ conditions are reached, at which the next garnet shell can be produced, THERIA_G finds the conditions at which the paragenesis changes to within $\pm 10^{-4 \circ} \mathrm{C}$ or \pm 20 bar, respectively. It stops the growth of the current shell at these conditions. In such a situation, the resulting thickness of the garnet shell is 
smaller than $\Delta r_{\text {shell }}$. The effective bulk rock composition is adjusted accordingly and the respective $P-T$ conditions are used as the starting point for the search of the next garnet shell.

\section{Modelling of intracrystalline diffusion}

In general, as garnet forms at changing $P-T$ conditions, successive garnet shells have different chemical compositions. This gives rise to garnet growth zoning, which may be modified subsequently by intracrystalline diffusion. To investigate these effects the relaxation of compositional gradients by intracrystalline diffusion in garnet is modelled throughout the entire $P-T-t$ path.

In general, for multicomponent diffusion, Fick's Second Law (Onsager 1945) takes the form of a parabolic partial differential equation

$\frac{\partial C_{i}}{\partial t}=\frac{\partial}{\partial x} \sum_{j=1}^{n-1} D_{i j}\left(\frac{\partial C_{j}}{\partial x}\right)$

where $C_{i}$ is the concentration of a component in an $n$ component system, $t$ is time, the $D_{i j} \mathrm{~s}$ are the interdiffusion coefficients, and $x$ is distance. In an $n$-component system, only $n-1$ components can diffuse independently.

The interdiffusion coefficients $D_{i j}$, are calculated following the method suggested by Lasaga (1979) for multicomponent ideal ionic solutions

$D_{i j}=D_{i}^{*} \Delta_{i j}-\left(\frac{D_{i}^{*} z_{i} z_{j} X_{i}}{\sum_{k=1}^{n} z_{k}^{2} X_{k} D_{k}^{*}}\right)\left(D_{j}^{*}-D_{n}^{*}\right)$

where $\delta_{i j}$ is the Kronecker delta $\left(\delta_{i j}=0\right.$ at $i \neq j$ and $\delta_{i j}=1$ at $i=j), z$ is the charge of the diffusing species, $X$ is the mole fraction of the component. $D^{*}{ }_{i}$ is the tracer diffusion coefficient of component $i$ and can be calculated from the Arrhenius relation

$D_{i}^{*}=D_{0} \exp \left(\frac{-E_{\mathrm{a}}-(P-1) \Delta V^{+}}{R T}\right)$

with the pre-exponential constant $D_{0}$, the activation energy of diffusion $E_{\mathrm{a}}$, at $1 \mathrm{bar}$, the activation volume of diffusion $\Delta V^{+}$, the universal gas constant $R$, and the temperature $T$.

For multicomponent diffusion in a spherical geometry Eq. (2.1) takes the form (Crank 1975)

$\frac{\partial C_{i}}{\partial t}=\frac{1}{r^{2}} \frac{\partial}{\partial r} \sum_{j}^{n-1} D_{i j} r^{2}\left(\frac{\partial C_{j}}{\partial r}\right)$

where $r$ corresponds to the radius of the sphere. Given that over a radius increment $\Delta r$, the variation in the concentration of component $i$ is small, the compositional dependence of the interdiffusion coefficients $D_{i j}$, can be neglected and expression (2.4) takes the form $\frac{\partial C_{i}}{\partial t}=\sum_{j}^{n-1} D_{i j}\left(\frac{\partial^{2} C_{j}}{\partial r^{2}}+\frac{2 \partial C_{j}}{r \partial r}\right)$

THERIA_G calculates diffusion of $\mathrm{Mn}, \mathrm{Mg}, \mathrm{Fe}$, and $\mathrm{Ca}$, whereby $\mathrm{Ca}$ is treated as the dependent component. Thus, a system of three equations may be written

$$
\begin{aligned}
& \frac{\partial C_{\mathrm{Mn}}}{\partial t}=D_{\mathrm{MnMn}} \quad\left(\frac{\partial^{2} C_{\mathrm{Mn}}}{\partial r^{2}}+\frac{2 \partial C_{\mathrm{Mn}}}{r \partial \partial}\right) \\
& +D_{\mathrm{MnFe}} \quad\left(\frac{\partial^{2} C_{\mathrm{Fe}}}{\partial r^{2}}+\frac{2 \partial C_{\mathrm{Fe}}}{r \partial \partial r}\right) \\
& +D_{\mathrm{MnMg}}\left(\frac{\partial^{2} C_{\mathrm{Mg}}}{\partial r^{2}}+\frac{2 \partial C_{\mathrm{Mg}}}{r \partial r}\right) \\
& \frac{\partial C_{\mathrm{Fe}}}{\partial t}=D_{\mathrm{FeMn}} \quad\left(\frac{\partial^{2} C_{\mathrm{Mn}}}{\partial r^{2}}+\frac{2 \partial C_{\mathrm{Mn}}}{r \partial \partial}\right) \\
& +D_{\mathrm{FeFe}} \quad\left(\frac{\partial^{2} C_{\mathrm{Fe}}}{\partial r^{2}}+\frac{2 \partial C_{\mathrm{Fe}}}{r \partial r}\right) \\
& +D_{\mathrm{FeMg}} \quad\left(\frac{\partial^{2} C_{\mathrm{Mg}}}{\partial r^{2}}+\frac{2 \partial C_{\mathrm{Mg}}}{r \partial \partial}\right) \\
& \frac{\partial C_{\mathrm{Mg}}}{\partial t}=D_{\mathrm{MgMn}} \quad\left(\frac{\partial^{2} C_{\mathrm{Mn}}}{\partial r^{2}}+\frac{2 \partial C_{\mathrm{Mn}}}{r \partial r}\right) \\
& +D_{\mathrm{MgFe}} \quad\left(\frac{\partial^{2} C_{\mathrm{Fe}}}{\partial r^{2}}+\frac{2 \partial C_{\mathrm{Fe}}}{r \partial \partial r}\right) \\
& +D_{\mathrm{MgMg}} \quad\left(\frac{\partial^{2} C_{\mathrm{Mg}}}{\partial r^{2}}+\frac{2 \partial C_{\mathrm{Mg}}}{r \partial r}\right)
\end{aligned}
$$

which THERIA_G solves numerically using a finite difference method (FDM). The Crank-Nicolson scheme (Crank and Nicolson 1947) is used as the discretization algorithm, whereby an irregular spatial grid is considered. As a result, the first part of the right-hand side of Eq. (2.6) can be expressed as

$$
\begin{aligned}
& \frac{D_{\mathrm{MnMn}}}{r \Delta r_{2} \Delta r_{1}} \\
& \times\left(\frac{r \Delta r_{1} C_{\mathrm{Mn}, n+1}^{m+1}-r \Delta r_{1} C_{\mathrm{Mn}, n}^{m+1}}{\left(\Delta r_{2}+\Delta r_{1}\right)}-\frac{r \Delta r_{2} C_{\mathrm{Mn}, n}^{m+1}+r \Delta r_{2} C_{\mathrm{Mn}, n-1}^{m+1}}{\left(\Delta r_{2}+\Delta r_{1}\right)}\right. \\
& +\frac{\left(\Delta r_{1}\right)^{2} C_{\mathrm{Mn}, n+1}^{m+1}-\left(\Delta r_{1}\right)^{2} C_{\mathrm{Mn}, n}^{m+1}}{\left(\Delta r_{2}+\Delta r_{1}\right)} \\
& \left.+\frac{\left(\Delta r_{2}\right)^{2} C_{\mathrm{Mn}, n}^{m+1}-\left(\Delta r_{2}\right)^{2} C_{\mathrm{Mn}, n-1}^{m+1}}{\left(\Delta r_{2}+\Delta r_{1}\right)}\right)+\frac{D_{\mathrm{MnMn}}}{r \Delta r_{2} \Delta r_{1}} \\
& \times\left(\frac{r \Delta r_{1} C_{\mathrm{Mn}, n+1}^{m}-r \Delta r_{1} C_{\mathrm{Mn}, n}^{m}}{\left(\Delta r_{2}+\Delta r_{1}\right)}-\frac{r \Delta r_{2} C_{\mathrm{Mn}, n}^{m}+r \Delta r_{2} C_{\mathrm{Mn}, n-1}^{m}}{\left(\Delta r_{2}+\Delta r_{1}\right)}\right. \\
& +\frac{\left(\Delta r_{1}\right)^{2} C_{\mathrm{Mn}, n+1}^{m}-\left(\Delta r_{1}\right)^{2} C_{\mathrm{Mn}, n}^{m}}{\left(\Delta r_{2}+\Delta r_{1}\right)} \\
& \left.+\frac{\left(\Delta r_{2}\right)^{2} C_{\mathrm{Mn}, n}^{m}-\left(\Delta r_{2}\right)^{2} C_{\mathrm{Mn}, n-1}^{m}}{\left(\Delta r_{2}+\Delta r_{1}\right)}\right),
\end{aligned}
$$

where $n$ and $m$ are nodes of a radius-time $(r-t)$ grid, respectively. The terms $\Delta r_{1}$ and $\Delta r_{2}$ correspond to the spatial steps at both sides of a specific grid node. To account for the thin shells that might result from changes in the garnet-bearing assemblages during an incremental step in $P$ and $T$, the spatial grid is treated as irregular. In 
principle, the irregularity of the $r-t$ grid contributes to the numerical error that stems from discretization of (2.5). Since the majority of the spatial steps $\Delta r_{1}$ and $\Delta r_{2}$ have the predefined size of $\Delta r_{\text {shell }}$, the numerical error is kept at a minimum. Nevertheless, the number of shells plays an essential role: the more shells a garnet contains, the smaller is the numerical imprecision that results from discretization.

If (2.7-2.8) are treated accordingly, the discretized form of (2.5) is obtained. Solution of this equation requires specification of initial and boundary conditions.

At the inner boundary $n=0$, Eq. (2.5) is replaced by

$\frac{\partial C_{i}}{\partial t}=\sum_{i}^{n-1} 3 D_{i j} \frac{\partial^{2} C_{j}}{\partial r^{2}}$

(Evans et al. 1999). In order to close the inner boundary symmetrically, a fictitious node $n_{f 1}=-1$ is introduced, which matches node $n=1$ with respect to its chemical composition and distance to $n=0$. Hence, at $n=0$

$$
\begin{aligned}
\Delta r_{1} & =\Delta r_{2} \\
C_{i, n-1}^{m} & =C_{i, n+1}^{m} \\
C_{i, n-1}^{m+1} & =C_{i, n+1}^{m+1} .
\end{aligned}
$$

The composition of garnet at the outer boundary is calculated by THERIAK for the current thermodynamically relevant bulk rock composition. This composition as well as the external conditions are held constant during the diffusion step. Therefore, a flux across the garnet/matrix boundary occurs, which is monitored to adjust the bulk rock composition accordingly after each diffusion step.

If a component $i$ is preferentially fractionated into garnet during growth, this will lead to the depletion of this component in the rock matrix. Such depletion must also be reflected by the chemical composition of the corresponding garnet growth increments. Due to the separation of the modelling of chemical fractionation during growth and intragranular diffusion as implemented in THERIA_G, the quantity of a component that should enter garnet in the course of the flux across the garnet/matrix boundary may exceed the size of the respective matrix reservoir. In such a case, garnet is closed for diffusional exchange with the matrix. If garnet is stable during the following $P-T$ increment, a garnet shell will grow that is devoid of the exhausted component. The interplay between garnet growth and intragranular diffusion produces the compositional gradient in the outer garnet growth increment, which is required by the successive depletion of the respective component in the rock matrix.

For a complete formulation of the system of Eqs (2.6-2.8) considering the boundary conditions and employing the Crank-Nicolson scheme, see the Electronic supplementary material. The system of equations is simultaneously solved after each time step $\Delta t$, for $C_{\mathrm{Mn}, n}^{m+1}$, $C_{\mathrm{Fe}, n}^{m+1}$, and $C_{\mathrm{Mg}, n}^{m+1}$ by Gaussian elimination. To account for appropriate accuracy, $\Delta t$ is calculated by

$\Delta t=\frac{\Delta r_{\text {shell }}}{10 D_{\mathrm{L}}}$,

where $D_{\mathrm{L}}$ corresponds to the largest of the interdiffusion coefficients $D_{i j}$, that are recalculated employing relation (2.2) and (2.3) after each time step. If $\Delta t$ is larger than the period of time that is related to the change of the external conditions $P$ and $T$ as defined in the $P-T-t$ path, a value, which is about ten times smaller than this period, is used.

\section{Consideration of garnet growth kinetics}

In THERIA_G modeling the garnet growth rate is solely controlled by the rate at which the rock evolves along its $P-T$ path. At any time during garnet growth, thermodynamic equilibrium is assumed to be maintained between the rim of the garnet crystals and the rock matrix. Therefore, the implementation of the THERIAK code (de Capitani and Brown 1987) to determine the garnet rim composition is well founded. As a consequence, THERIA_G considers component transport in the rock matrix and interface reactions to be fast relative to garnet growth. In distributing the newly formed garnet it is assumed that the radial growth rate during a specific growth increment is constant for all garnet porphyroblasts. This assumption is motivated by theoretical considerations (Kretz 1974) and by empirical evidence (Kretz 1993; Chernoff and Carlson 1997; Spear and Daniel 1998). Hence, for a given relative CSD of garnet and at the respective point in $P-T-t$ space, THERIA_G distributes the newly formed volume of garnet onto the surfaces of the existing garnet crystals such that the radial increase is the same for each individual. As a result, the Mn content at the centres of garnet crystals of progressively smaller size decreases. Moreover, because the growth of all garnet crystals finishes at the same time, all garnet rims have the same composition.

To simulate the formation of progressively smaller garnet crystals as part of a garnet population, THERIA_G repeatedly initiates nucleation of garnet. Nucleation of a group of garnet crystals occurs as soon as the garnet individuals that originate from the former nucleation event exceed the size of their radius class as defined by the relative CSD (Fig. 1). The required input parameters to model the formation of a garnet population are the number of garnet radius classes, the corresponding nucleation densities as well as the size range of the radius classes. It should be noted that only a relative CSD is used as an input; the actual size ranges of the individual radius classes result from the garnet growth simulation. 
In general, THERIA_G considers garnet nucleation as an episodic process, the recurrence of which can be controlled by the choice of the number and the size of the garnet radius classes that are to be formed. That is, in contrast to Cashman and Ferry (1988), garnet CSDs are not interpreted as the result of the growth of larger individuals on the expense of smaller ones but they are treated as resulting from variations in garnet nucleation rates during garnet growth. If - theoretically-an infinite number of garnet size classes and an infinitesimally small value for the size of the radius classes is used, garnet nucleation can be seen as a continuous process with rate fluctuations.

\section{Application of THERIA_G}

To exemplify the capabilities of THERIA_G, garnet growth simulations are done for the average metapelite of Shaw (1956) (Table 1).

The calculated equilibrium phase relations are shown in Fig. 2. For phase diagram calculations the bulk rock composition was taken as the effective composition, i.e. the calculated phase relations represent a situation before or at the incipient stage of garnet growth. Figure 2 also shows the $P-T$ loops along which garnet growth is simulated.

$\mathrm{SiO}_{2}$ and $\mathrm{H}_{2} \mathrm{O}$ were considered as excess components, implying saturation of the system with respect to quartz and an aqueous fluid along the entire $P-T$ path. To ensure that most of the common rock-forming minerals in a metapelite can be considered adequately, calculations were done in the simplified model system $\mathrm{MnO}-\mathrm{Na}_{2} \mathrm{O}-$ $\mathrm{CaO}-\mathrm{K}_{2} \mathrm{O}-\mathrm{FeO}-\mathrm{MgO}-\mathrm{Al}_{2} \mathrm{O}_{3}-\mathrm{SiO}_{2}-\mathrm{H}_{2} \mathrm{O}-\mathrm{TiO}_{2}$ (MnNCFMASHT) using thermodynamic data of Holland and Powell (1998) (thermodynamic database of THERMOCALC, version 3.21). The following mixing models and notations were applied: Grt [garnet; Holland and Powell (1998)], Pl [plagioclase; Newton et al. (1980)], Bt [biotite; Powell and Holland (1999), extended to cover Fe and Mn solutions], St [staurolite; Holland and Powell (1998), extended to cover Mn solutions], Phng (phengite, following the description at http://www.esc.cam.ac.uk/astaff/holland/ ds5/muscovites/mu.html), Ilm (ilmenite, ideal ilmenitegeikiellite-pyrophanite solution), ky (kyanite), and (andalusite), sill (sillimanite), cz (clinozoisite), and qtz (quartz). For the description of the solution model for Chl (chlorite) the reader is referred to the Electronic supplementary material. For modelling intragranular diffusion of $\mathrm{Fe}, \mathrm{Mg}$ and $\mathrm{Mn}$ in garnet the diffusion coefficients of Chakraborty and Ganguly (1992) were used. Following the approach of Loomis et al. (1985) and Florence and Spear (1991), $D^{*} \mathrm{Ca}$ was set equal to $D^{*} \mathrm{Fe} / 2$.

To asses the influence of time on the degree of homogenization of garnet growth zoning through intragranular diffusion, different heating/cooling rates were used for two $P-T$ paths (loop A and loop B in Fig. 2 as well as Tables 2, 3).

\section{Garnet growth along $P-T$ loop A}

Figure 3 shows the influence of the heating/cooling rate on the chemical composition of the largest garnet crystal that grew along $P-T$ loop A (Fig. 2) for the theoretical relative CSD shown in Fig. 1 (CSD1). Similar CSD relations are reported by several authors (e.g. Kretz 1966, 1993; Cashman and Ferry 1988) for a number of metamorphic minerals. Figure 3 clearly shows that the growth zoning of the largest garnet in the corresponding rock volume is significantly modified at a heating/cooling rate of $\pm 5^{\circ} \mathrm{C}$ $\mathrm{My}^{-1}$. In garnet, diffusion of $\mathrm{Mn}$ and $\mathrm{Fe}$ is substantially faster than diffusion of $\mathrm{Ca}$ and $\mathrm{Mg}$ (Chakraborty and Ganguly 1992). In Fig. 3 the modification of garnet growth zoning is more pronounced for $\mathrm{Mn}$ and $\mathrm{Fe}$ than for $\mathrm{Mg}$ and $\mathrm{Ca}$, accordingly. At heating/cooling rates larger than $\pm 20^{\circ} \mathrm{C} \mathrm{My}^{-1}$ modification of the growth zoning by intracrystalline diffusion becomes negligible.

The original composition of the core regions of the oldest garnet individuals is largely preserved even at slow heating/ cooling rates. This is due to the fact that during the incipient stages of garnet growth the increments in $P$ and $T$ needed to produce a shell of thickness $\Delta r_{\text {shell }}$ are relatively small. As a consequence the innermost portions of the garnets form over a small range of $P-T$ conditions, and core compositions are rather homogeneous. Therefore compositional gradients and diffusional fluxes are small (Fig. 4).

During later stages of garnet growth the $P$ and $T$ increments needed to produce successive shells of thickness $\Delta r_{\text {shell }}$ increase. This is why compositional gradients and the resulting diffusional fluxes are higher in small garnet crystals that originate at later stages in the nucleation interval than in garnet individuals, which nucleated earlier. Hence, modification of the growth zoning becomes successively more pronounced for younger garnet crystals (Fig. 5).

Table 1 Bulk rock composition of the average metapelite of Shaw (1956) (wt\%)

\begin{tabular}{lllllllllll}
\hline $\mathrm{SiO}_{2}$ & $\mathrm{Al}_{2} \mathrm{O}_{3}$ & $\mathrm{Fe}_{2} \mathrm{O}_{3}$ & $\mathrm{MnO}$ & $\mathrm{MgO}$ & $\mathrm{CaO}$ & $\mathrm{Na}_{2} \mathrm{O}$ & $\mathrm{K}_{2} \mathrm{O}$ & $\mathrm{H}_{2} \mathrm{O}$ & $\mathrm{CO}_{2}$ & $\sum$ \\
\hline 59.77 & 16.57 & 6.53 & 0.07 & 2.62 & 2.17 & 1.73 & 3.53 & 2.49 & 5.16 & 100.64 \\
\hline
\end{tabular}


Fig. $2 \quad P-T$ phase diagram section with the garnet stability field shaded in grey and calculated garnet compositions and total vol \% of garnet for the average metapelite of Shaw (1956) (Table 1); the dashed lines indicate the $P-T$ loops along which garnet growth is simulated (see Tables 2, 3 for detailed $P-T$ values); $\mathrm{SiO}_{2}$ and $\mathrm{H}_{2} \mathrm{O}$ were considered as excess components; the calculations were done with the DOMINO software (de Capitani 1994), which-similarly to

THERIA_G-employs the THERIAK code for Gibbs free energy minimization
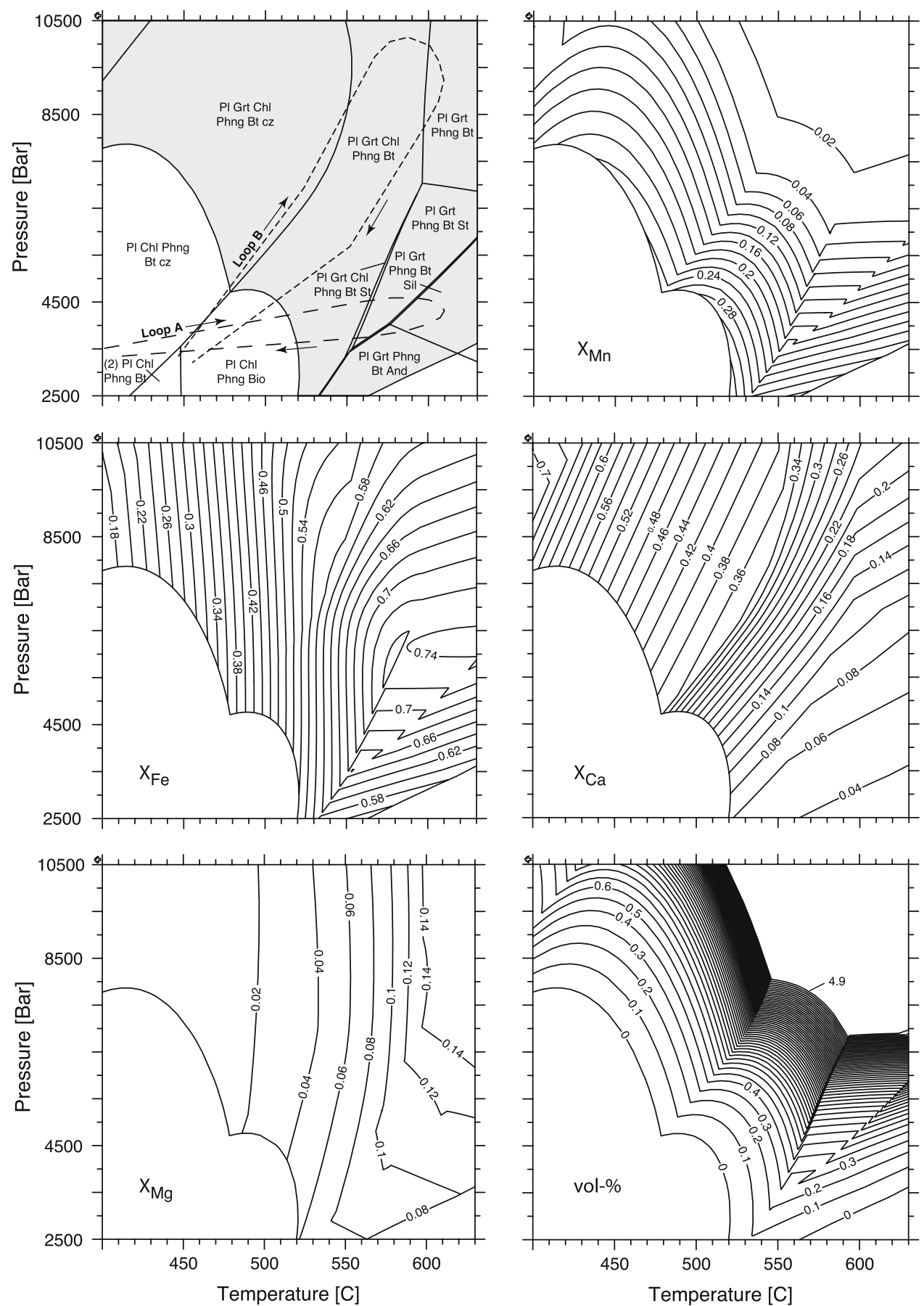

In our example, garnet crystals that pertain to radius class 3 are the first garnet individuals, where modification of the growth zoning in the core region is readily detected for a heating/cooling rate of $\pm 5^{\circ} \mathrm{C} \mathrm{My}^{-1}$ (Figs. 5, 6).

For all garnet porphyroblasts, which started to grow subsequent to garnet from radius class 3 , the growth zoning was modified substantially by intragranular diffusion. For crystals of radius class 10 intragranular diffusion even lead to a complete obliteration of the $\mathrm{Ca}$ and $\mathrm{Mg}$ growth zoning.
In this scenario, the initial compositions of all contemporaneously growing garnet shells and the compositional gradients between successive shells are similar for all garnets (compare Carlson 1989; Kretz 1993; Spear and Daniel 1998). As a consequence, the initial composition of a given succession of growth shells that represents the core region of a garnet that grew at a late stage in the thermal history may correspond to the growth zoning of a peripheral region in a previously formed garnet (Fig. 5). 
Table $2 P-T-t$ triplets that represent the metamorphic $P-T-t$ paths for loop A (Fig. 2)

Table $3 \quad P-T-t$ triplets that represent the metamorphic $P-T-t$ paths for loop B (Fig. 2)

\begin{tabular}{|c|c|c|c|c|}
\hline \multirow[t]{2}{*}{$T\left({ }^{\circ} \mathrm{C}\right)$} & \multirow[t]{2}{*}{$P$ (bar) } & \multicolumn{3}{|c|}{$t$ (My) for a heating/cooling rate of } \\
\hline & & $\pm 50^{\circ} \mathrm{C} \mathrm{My}^{-1}$ & $\pm 20^{\circ} \mathrm{C} \mathrm{My}^{-1}$ & $\pm 5^{\circ} \mathrm{C} \mathrm{My}^{-1}$ \\
\hline 400.00000 & 3500.00000 & 0.00000 & 0.00000 & 0.00000 \\
\hline 560.00000 & 4500.00000 & 3.20000 & 8.00000 & 32.00000 \\
\hline 577.25424 & 4576.92308 & 3.54508 & 8.86271 & 35.45085 \\
\hline 592.20339 & 4576.92308 & 3.84407 & 9.61017 & 38.44068 \\
\hline 600.74576 & 4532.05128 & 4.01492 & 10.03729 & 40.14915 \\
\hline 608.57627 & 4403.84615 & 4.17153 & 10.42881 & 41.71525 \\
\hline 610.00000 & 4307.69231 & 4.20000 & 10.50000 & 42.00000 \\
\hline 610.10000 & 4300.00000 & 4.20200 & 10.50500 & 42.02000 \\
\hline 607.50847 & 4153.84615 & 4.25383 & 10.63458 & 42.53831 \\
\hline 598.96610 & 4006.41026 & 4.42468 & 11.06169 & 44.24678 \\
\hline 585.79661 & 3865.38462 & 4.68807 & 11.72017 & 46.88068 \\
\hline 560.88136 & 3730.76923 & 5.18637 & 12.96593 & 51.86373 \\
\hline 404.67359 & 3316.40625 & 8.31053 & 20.77632 & 83.10528 \\
\hline
\end{tabular}

\begin{tabular}{|c|c|c|c|c|}
\hline \multirow[t]{2}{*}{$T\left({ }^{\circ} \mathrm{C}\right)$} & \multirow[t]{2}{*}{$P$ (bar) } & \multicolumn{3}{|c|}{$t$ (My) for a heating/cooling rate of } \\
\hline & & $\pm 50^{\circ} \mathrm{C} \mathrm{My}^{-1}$ & $\pm 20^{\circ} \mathrm{C} \mathrm{My}^{-1}$ & $\pm 5^{\circ} \mathrm{C} \mathrm{My}^{-1}$ \\
\hline 446.17989 & 3345.11121 & 0.00000 & 0.00000 & 0.00000 \\
\hline 523.58062 & 6935.51254 & 1.54801 & 3.87004 & 15.48015 \\
\hline 560.04451 & 9270.83333 & 2.27729 & 5.69323 & 22.77292 \\
\hline 567.55193 & 9739.58333 & 2.42744 & 6.06860 & 24.27441 \\
\hline 577.10682 & 10062.50000 & 2.61854 & 6.54635 & 26.18539 \\
\hline 588.02671 & 10145.83333 & 2.83694 & 7.09234 & 28.36936 \\
\hline 601.33531 & 9968.75000 & 3.10311 & 7.75777 & 31.03108 \\
\hline 607.13650 & 9625.00000 & 3.21913 & 8.04783 & 32.19132 \\
\hline 610.10000 & 9229.16667 & 3.27840 & 8.19601 & 32.78402 \\
\hline 606.79525 & 8781.25000 & 3.34450 & 8.36124 & 33.44497 \\
\hline 598.26409 & 8250.00000 & 3.51512 & 8.78780 & 35.15120 \\
\hline 551.91482 & 5687.51208 & 4.44211 & 11.10526 & 44.42106 \\
\hline 454.81836 & 3210.71116 & 6.38403 & 15.96009 & 63.84035 \\
\hline
\end{tabular}

In general, the number of garnet crystals per rock volume, which grew early in the thermal history, is markedly smaller then the amount of younger crystals in the rock for similar garnet CSD relations (Fig. 1). This needs to be taken into account, if $P-T$ estimates for the incipient stages of garnet growth are to be determined from primary core chemistries of garnet that grew in a bulk rock chemistry similar to the average metapelite of Shaw (1956) and experienced a comparable geothermal history.

Garnet growth simulation along $P-T$ loop A, which were forced to develop a theoretical relative CSD as illustrated in Fig. 7 (CSD2), produces bigger garnet individuals then the calculations for CSD1 (Fig. 1). Even though the total amount of garnet per rock volume is the same for both CSDs, the simulation that is based on CSD2 results in slightly different garnet compositions (Fig. 8). The most conspicuous difference is the $\mathrm{Mg}$ and $\mathrm{Ca}$ zoning of the youngest garnet crystals, which is not completely homogenized.

Garnet growth along loop A ceases when staurolite becomes stable. From this point on, the $P-T$ path passes below the low pressure limit of the garnet stability field (see Fig. 9). Note that the garnet stability field in Fig. 9 is substantially smaller than in Fig. 2. This is due to changes in the effective bulk rock composition through chemical fractionation during garnet growth and through diffusional fluxes between garnet and the matrix. The latter strongly depends on the extent of relaxation of compositional gradients through intragranular diffusion and, hence, on CSD and heating/cooling rate. Both parameters were specified for constructing Fig. 9. 

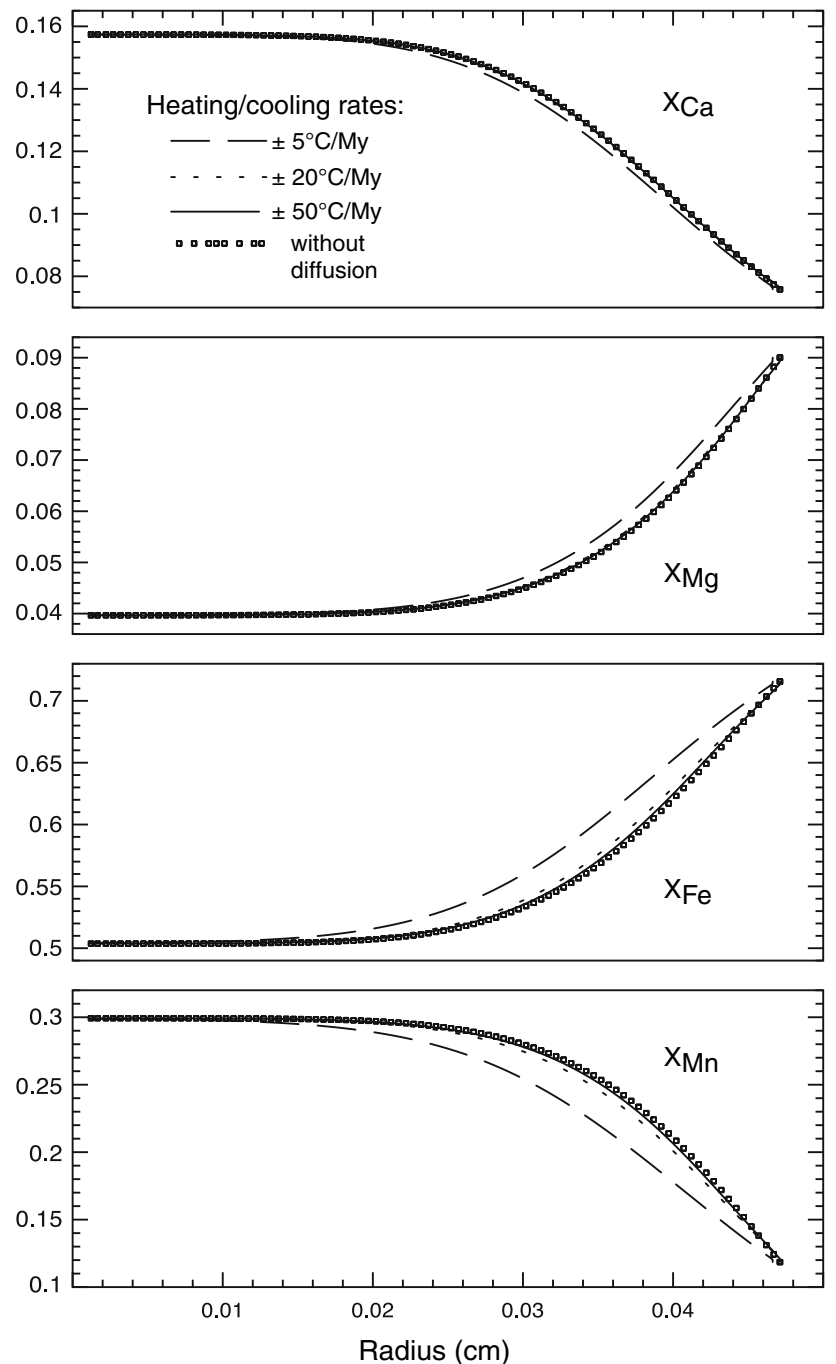

Fig. 3 Influence of the heating/cooling rate on the chemical composition of the largest garnet crystal (garnet of radius class 1) illustrated in Fig. 1. The $P-T-t$ paths shown in Table 2 are used. $\Delta r_{\text {shell }}$ is ca. $5 \mu \mathrm{m}$. The compositional profile, which illustrates growth zoning, is marked with symbols

\section{Garnet growth along $P-T$ loop B}

To simulate the growth of garnet along $P-T$ loop B (Fig. 2), a relative garnet CSD relation is used which exactly matches CSD1 (Fig. 1), but differs with respect to the size of the radius classes. In order to limit the number of different radius classes to a maximum of 10 , a size of $150 \mu \mathrm{m}$ is used for each radius class.

The calculated initial compositional profile of garnet from radius class 4 and the influence of intragranular diffusion for different heating/cooling rates on garnet growth zoning is illustrated in Fig. 10.

At a heating/cooling rate of $\pm 5^{\circ} \mathrm{C} \mathrm{My}^{-1}$ the $\mathrm{Fe}$ and $\mathrm{Mn}$ concentrations in the garnet core are substantially reduced as compared to the initial composition.

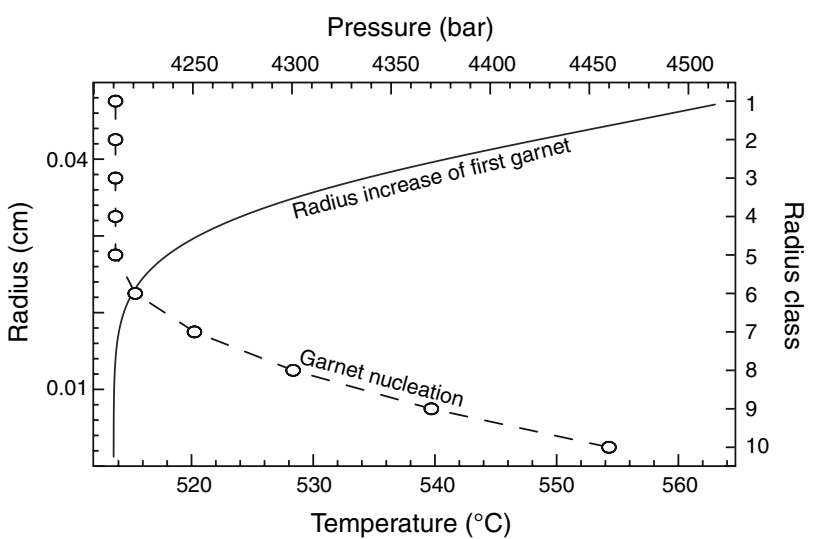

Fig. 4 Relation between changes of the $P-T$ conditions and the size of the oldest garnet crystal (solid line) calculated for $P-T$ loop A (Fig. 2; Table 2) and CSD1 (Fig. 1). In addition, the $P-T$ conditions at the time of nucleation of garnet from the different size classes are displayed (open circles along the dashed line)

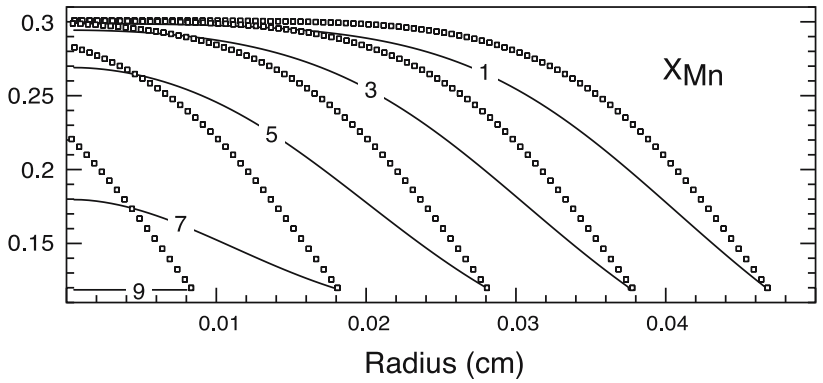

Fig. 5 Influence of diffusional relaxation in garnet (lines) on garnet growth zoning (symbols) illustrated for $X_{\mathrm{Mn}}$ considering CSD1 (Fig. 1) and a heating/cooling rate of $\pm 5^{\circ} \mathrm{C} \mathrm{My}^{-1}$ along loop A. Numbers correspond to the labels of the radius classes denoted in Fig. $1 . \Delta r_{\text {shell }}$ is ca. $5 \mu \mathrm{m}$

The number of garnet porphyroblasts that pertain to radius class 4 is substantially larger than the number of older crystals, which-in the course of petrographic investigations - may lead to an overestimation of the relative age of individuals from this size class.

In addition, the point along loop B where clinozoisite becomes unstable is indicated in Fig. 10. Clinozoisite as well as plagioclase are the main suppliers of $\mathrm{Ca}$ for the formation of the grossular component of garnet. When clinozoisite disappears the Ca supply decreases substantially. As a consequence the grossular content of garnet decreases rapidly, whereas $\mathrm{X}_{\mathrm{Mg}}$ and $\mathrm{X}_{\mathrm{Fe}}$ increase concomitantly.

The calculated compositional profiles of all the garnet crystals that grew along $P-T$ loop B at a heating/cooling rate of $\pm 5^{\circ} \mathrm{C} \mathrm{My}^{-1}$ are shown in Fig. 11 .

Garnet porphyroblasts that pertain to the radius classes 7-10 are completely homogenized with respect to their $\mathrm{Mn}$ zoning. It is interesting to note that garnet from radius class 

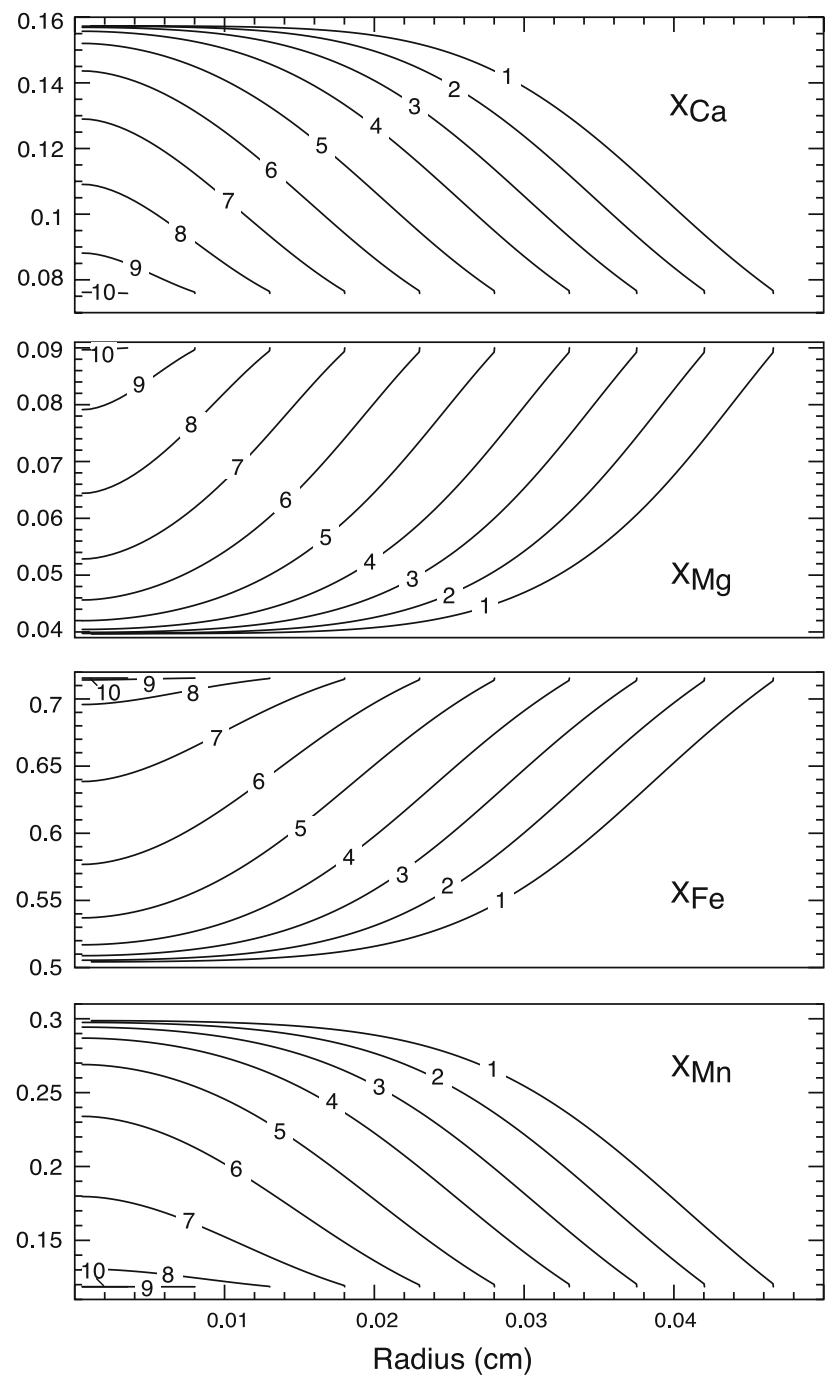

Fig. 6 Compositional profiles of the garnet porphyroblasts computed for CSD1 (Fig. 1) and a heating/cooling rate of $\pm 5^{\circ} \mathrm{C} \mathrm{My}{ }^{-1}$ along loop A. Numbers correspond to the labels of the radius classes denoted in Fig. 1. $\Delta r_{\text {shell }}$ is ca. $5 \mu \mathrm{m}$

7 is approximately as big as the first garnet that grew along $P-T$ loop A for both CSD1 and CSD2 (Figs. 1, 7). However, the zoning pattern of garnet that grew along loop A is only slightly modified by intragranular diffusion even though it grew at the same heating/cooling rate and experienced exactly the same maximum temperature during its geothermal history (Tables 2, 3). This difference can be explained by the fact that the Mn concentrations show notably larger gradients for garnets that grow along $P-T$ loop B than for those which grow along loop A.

Furthermore, due to the fact that the amount of garnet produced along $P-T$ loop B is larger than the amount of garnet that is formed along $P-T$ loop $\mathrm{A}$, the oldest garnet individuals originating along $P-T$ loop B are significantly larger then those, which grew along $P-T$ loop A. Because of the garnet growth model implemented in THERIA_G,

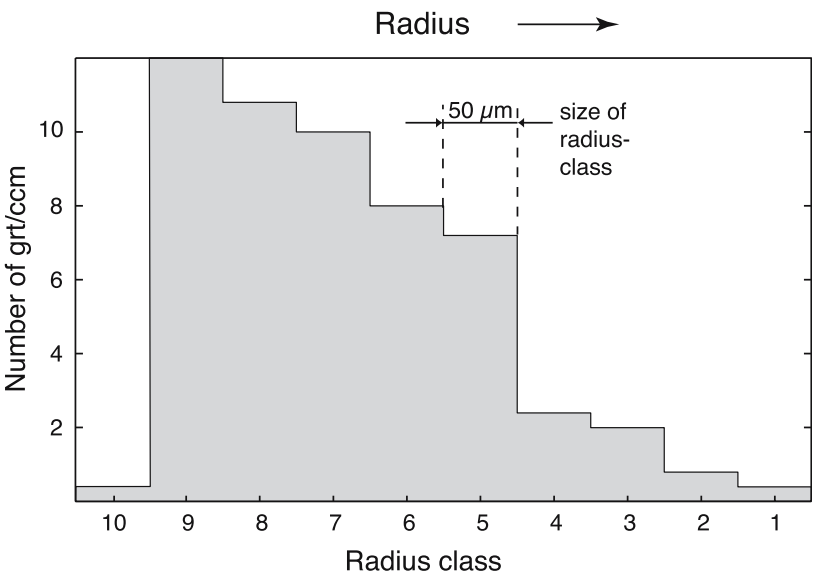

Fig. 7 Relative garnet crystal size frequency distribution (CSD2) used for the calculation of garnet chemical composition illustrated in Fig. 8

the steep chemical gradient is shifted into the core regions of garnet, which nucleated late in the nucleation interval. Therefore, the effectiveness of homogenisation by diffusion is substantially enhanced and may lead to complete homogenisation in garnet of radius classes 7-10.

To account for a scenario where garnet nucleation ceases before garnet growth ends, the theoretical relative CSD1 (Fig. 1) is used and a value of $100 \mu \mathrm{m}$ is employed for the size of the radius class. This approach terminates in the decrease of the size of garnet grains from radius classes 1 to 4 and leads to the enlargement of younger grains if compared with the former results (Figs. 11, 12). The $P-T$ conditions, at which garnet nucleation stops, are marked in Fig. 13.

A further consequence of the condensed period of garnet nucleation is the reduction of the garnet stability field. In contrast to concomitant garnet nucleation and growth, the formation of garnet ceases at conditions before the prograde part of the $P-T$ path ends (filled circle in Fig. 13). This may be explained by remarkable intragranular diffusional fluxes in garnet crystals, which originated from late stages of the geothermal history. In such cases, the chemical composition of the matrix changes, if the diffusion module implemented in THERIA_G regards the outer boundary of the garnet crystals as open. That is, both processes, chemical fractionation associated with garnet growth and effective diffusional relaxation in garnet, modify the thermodynamically relevant bulk rock composition, but both processes operate in opposite directions.

\section{Discussion}

The main assumption behind THERIA_G modelling is that the garnet crystal, which is treated as an undeformed sphere, devoid of any mineral inclusions and cracks, has a 

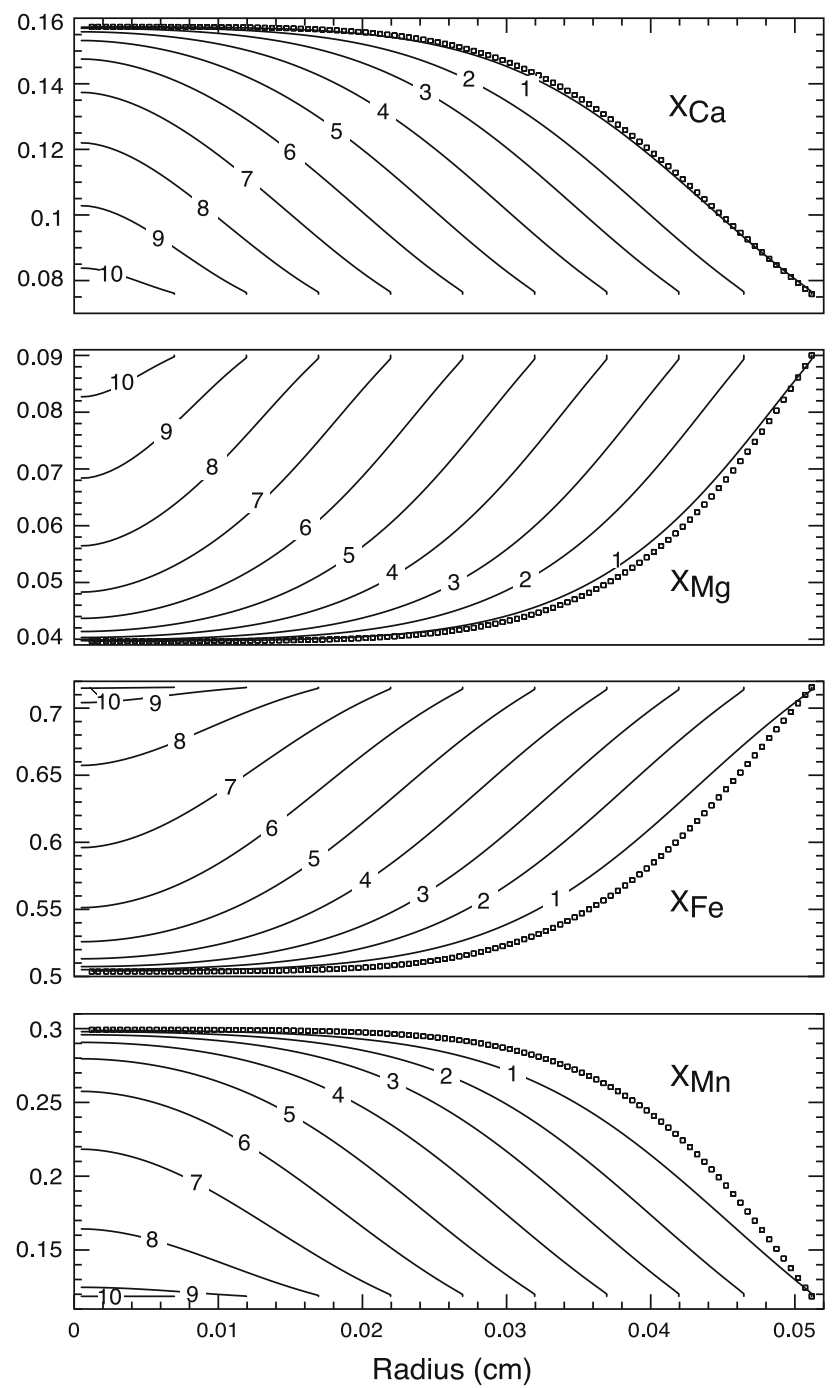

Fig. 8 Compositional profiles of the garnet porphyroblasts computed for CSD2 (Fig. 7) and a heating/cooling rate of $\pm 5^{\circ} \mathrm{C} \mathrm{My}^{-1}$ along $P$ $T$ loop A. The compositional profile of the oldest garnet crystal, which illustrates garnet growth zoning, is marked with symbols. Numbers correspond to the labels of the radius classes denoted in Fig. 7. $\Delta r_{\text {shell }}$ is ca. $5 \mu \mathrm{m}$

rim that is always in thermodynamic equilibrium with the rock matrix during growth. In that respect, the rock volume is considered as a closed chemical system. For a thermodynamical homogeneous rock matrix, intergranular diffusion of the reacting species has to be faster than the rates of precursor decomposition and garnet precipitation. This is likely as long as garnet grows along a prograde $P-T$ path in a hydrous rock, which experienced only low grade metamorphic conditions prior to garnet formation. In such a case, gradients in the chemical potential of each reacting species that form at the garnet/matrix interface are small and thermodynamic equilibrium can be considered to be maintained over volume domains of hand specimen size or even on a larger scale.

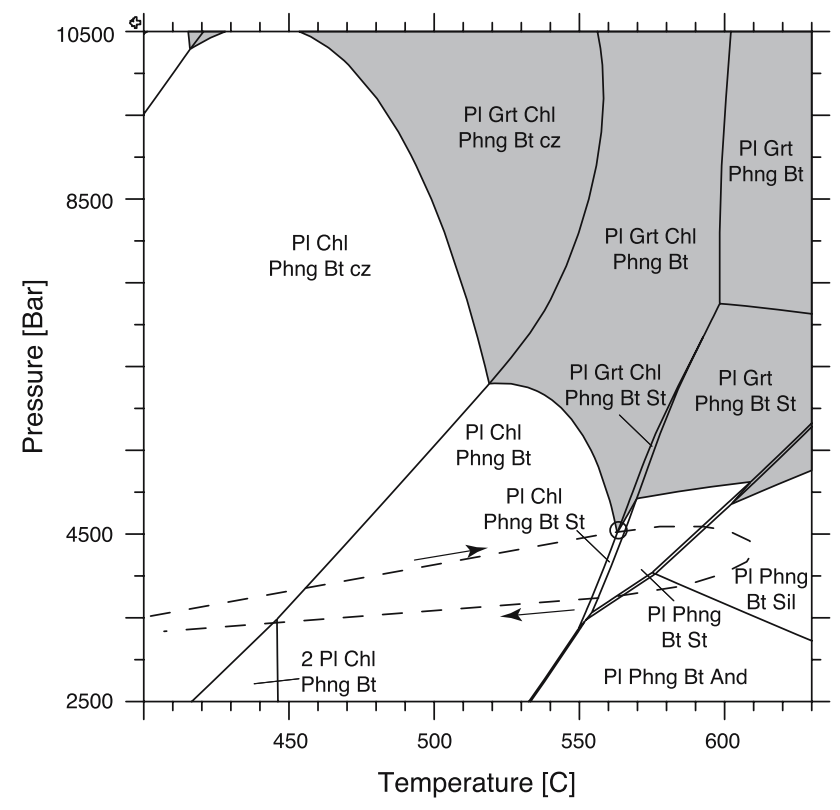

Fig. $9 P-T$ phase diagram section illustrating the equilibrium phase relations and $P-T$ conditions at which garnet growth ceases along $P$ $T$ loop A for a heating/cooling rate of $\pm 5^{\circ} \mathrm{C} \mathrm{My}^{-1}$ and CSD1 (Fig. 1). The conditions where garnet first becomes unstable are marked with an open circle

In general, the rate of garnet crystallisation is effected by the rates of material transport in the rock matrix and by the rates of interface reactions at the surfaces of precursor phases and the evolving garnet porphyroblast. If the growth rate of a garnet porphyroblast is controlled by reactions at the surface of the growing crystal, then the growth rate law follows the form

$\frac{d V}{d t} \approx A k \Delta_{r} G$

where $V$ and $A$ correspond to volume and surface of the growing crystal, respectively, $k$ is a rate constant and $\Delta_{r} G$ is the driving force for the reaction (compare Kretz 1974, 1993; Carlson 1989).

For spherical geometry (4.1) takes the form

$\frac{d r}{d t} \approx k \Delta_{r} G$,

which indicates that for interface-controlled growth crystals of all sizes grow with the same radial rate. Simulations performed by Spear and Daniel (1998) using the geometric limitations of (4.2) and varying nucleation densities during garnet growth yielded compositional profiles, which are parallel at all concentrations for the crystals of different sizes. Such a geometric relation was repeatedly observed for $\mathrm{MnO}, \mathrm{FeO}$, and $\mathrm{MgO}$ in garnet of metapelites (e.g. Kretz 1993; Chernoff and Carlson 1997; Spear and Daniel 1998; Zeh 2006). As described above, THERIA_G considers this relation for the distribution of newly formed 




Fig. 10 Influence of different heating/cooling rates on the chemical composition of garnet that pertains to the fourth radius class and grew along $P-T$ loop B (Fig. 2). $\Delta r_{\text {shell }}$ is ca. $10 \mu \mathrm{m}$. One change of the equilibrium assemblage is marked. The CSD encountered along loop $\mathrm{B}$ corresponds to the one displayed in Fig. 1, where a value of $150 \mu \mathrm{m}$ is used as the size of the radius class. The symbols mark growth zoning

garnet on pre-existing crystals during each growth increment. However, due to the lack of information on interface kinetics the variations of the chemical potentials of the reacting species around garnet, which stem from the reactions at the surface of garnet, cannot be taken into account sufficiently.

THERIA_G modelling to simulate garnet growth in dehydrated rocks is considered problematic because dehydration strongly influences the efficiency of intergranular material transport (Keller et al. 2007). If transport of material is sluggish compared to the rate of interface reactions, the rate of garnet growth may be controlled by intergranular diffusion and, as a consequence, gradients in the chemical potentials of the reacting species evolve and
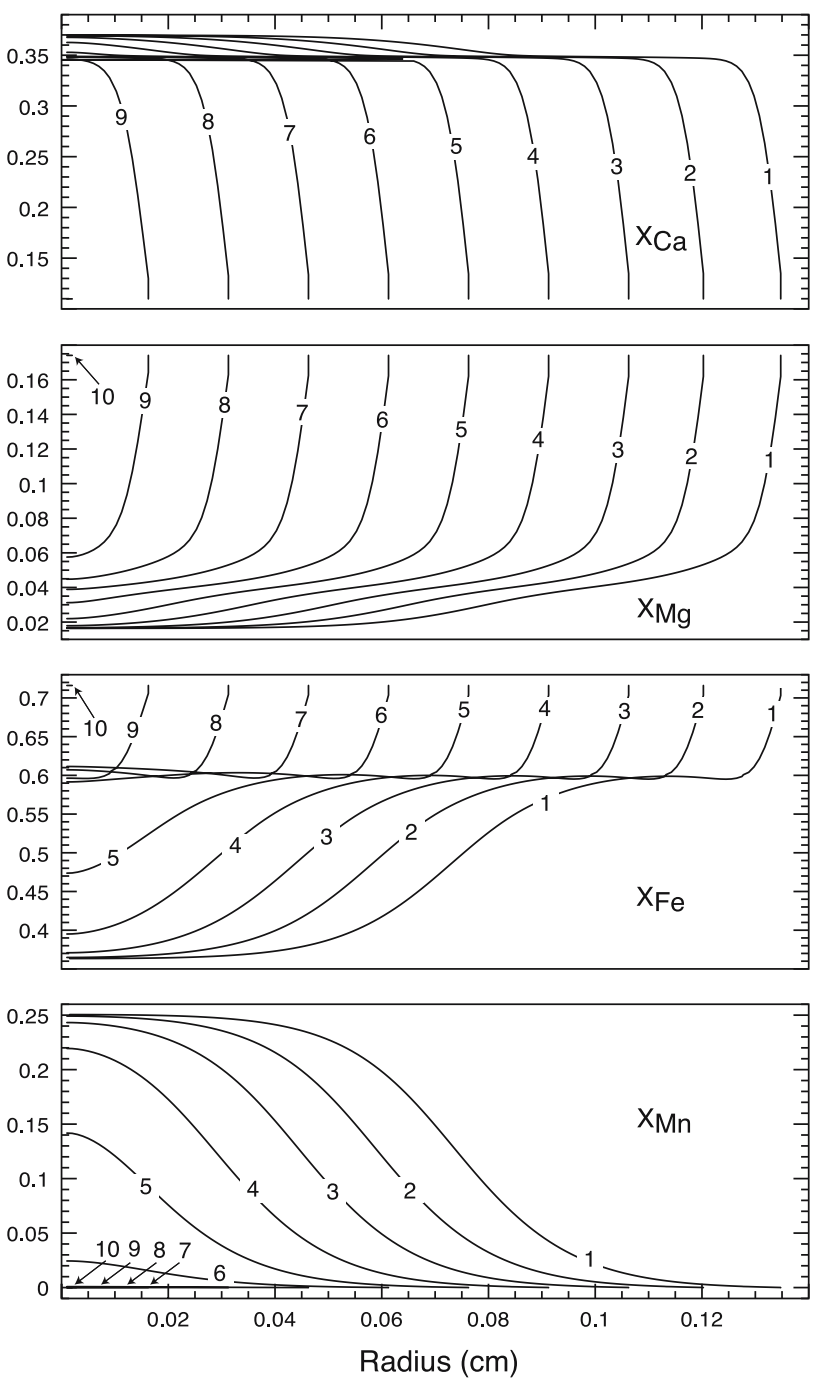

Fig. 11 Compositional profiles of the garnet porphyroblasts computed for CSD1 (Fig. 1) with $150 \mu \mathrm{m}$ as the size of the radius class and a heating/cooling rate of $\pm 5^{\circ} \mathrm{C} \mathrm{My}^{-1}$ along $P-T$ loop B. Numbers correspond to the labels of the radius classes denoted in Fig. 1. $\Delta r_{\text {shell }}$ is ca. $10 \mu \mathrm{m}$

progressively enlarge in the vicinity of the growing garnet (Carlson 1989; Spear and Daniel 2001). In such cases the size of equilibration domains may be so small that a single garnet porphyroblast pertains to different equilibration domains. Systematic variations of garnet rim compositions give evidence for such behaviour and have been reported from retrograde reactions in high-grade rocks (Hauzenberger et al. 2005; Keller et al. 2007) and from garnet rim growth at eclogite facies conditions (Keller et al. 2006). It may be speculated that in dehydrated rocks the nucleation of garnet individuals may follow a more complex law than considered in THERIA_G, where smaller crystals originate from a late stage in the nucleation history. Besides sluggish intergranular material transport, processes such as Ostwald ripening may influence the garnet CSD. In addition, 

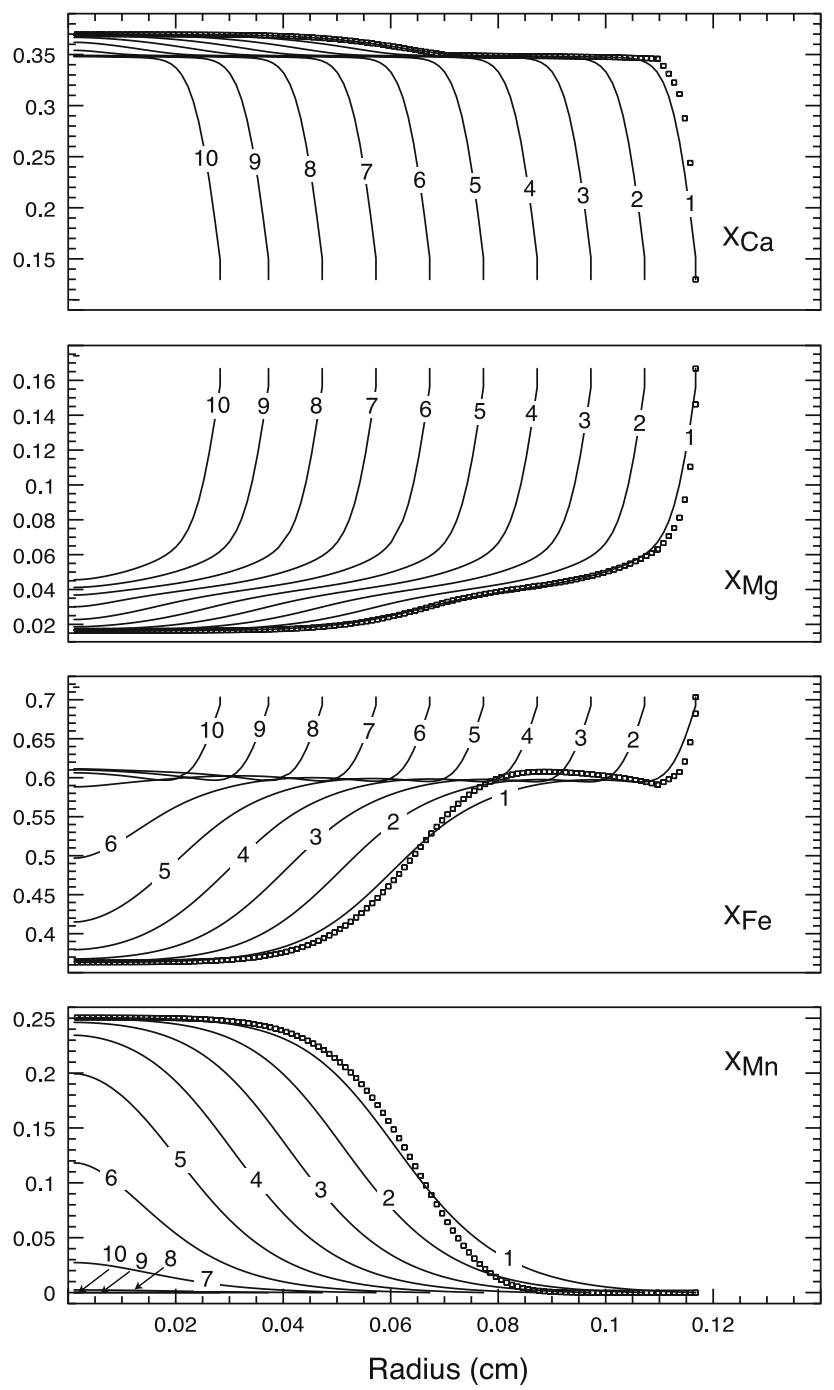

Fig. 12 Compositional profiles of the garnet porphyroblasts calculated for the case that garnet nucleation ceases prior to garnet growth (see text for explanation). Garnet is forced to produce CSD1 (Fig. 1) with $100 \mu \mathrm{m}$ as the size of the radius class along $P-T$ loop B. The heating/cooling rate is $\pm 5^{\circ} \mathrm{C} \mathrm{My}^{-1}$. For $\Delta r_{\text {shell }}$ a value of $10 \mu \mathrm{m}$ was chosen

competitive growth of several neighbouring garnet grains may occur (Carlson 1991).

The radial growth-rate law for intergranular diffusioncontrolled growth takes the form

$\frac{d r}{d \sqrt{t}} \approx k \Delta_{r} G$

(compare Christian 1975). Reformulation of (4.3) yields

$\frac{d r}{d t} \approx \frac{k}{r} \Delta_{r} G$

which indicates that for diffusion-controlled garnet growth the radial rate depends on the size of the garnet crystals, i.e. smaller garnet crystals will grow faster than large porphyroblasts.



Fig. $13 P-T$ phase diagram section illustrating the equilibrium phase relations and $P-T$ conditions at which garnet nucleation and growth finish along $P-T$ loop B for a heating/cooling rate of $\pm 5^{\circ} \mathrm{C} \mathrm{My}$ (open circle). Garnet growth was forced to develop CSD1 (Fig. 1) with a value of $150 \mu \mathrm{m}$ as the size of the radius class. In addition, the filled circle marks the $P-T$ conditions, at which garnet growth ceases, if nucleation stops prior to garnet growth (star). For this simulation, CSD1 (Fig. 1) was used with a value of $100 \mu \mathrm{m}$ as the size of the radius class (see text for explanations)

The radius-rate relation illustrated in Fig. 4 directly results from the quasi-linear increase of garnet volume with time assuming a constant heating/cooling rate and following the principles of equilibrium thermodynamics. Departure from the linear relationship between garnet volume and temperature only occurs at conditions, at which the composition of the equilibrium phase assemblage changes. These findings strongly conflict with the suggestion of Kretz (1974, 1993). In Kretz (1974) it is stated that 'the garnet production rate is highly acceleratory' (his Fig. 1).

Because in our model the matrix is assumed to be thermodynamically homogeneous with fast component diffusion, the simulation of retrograde exchange reactions between the rim of garnet and specific matrix phases (e.g. Florence and Spear 1995; Keller et al. 2007) is not implemented. However, since this process is commonly restricted to the outermost few $10-50 \mu \mathrm{m}$, its contribution to the principal compositional configuration of garnet is small.

It is important to note that resorption processes may strongly modify garnet chemical composition and morphology. Even along the prograde part of a $P-T$ path, periods of garnet instability may occur framed by stages of garnet stability (Gaidies et al. 2007). However, since information on the kinetics of garnet resorption is scarce, 
the influence of resorption during periods of garnet instability is not considered in our model.

In addition, open system behaviour during prograde metamorphic evolution may influence the thermodynamically effective bulk rock composition and the chemical composition of garnet. This is not considered in the THERIA_G model but might explain the possible differences between calculated and observed garnet composition.

Our simulations predict compositional profiles for the oldest garnet in a given volume of rock to be marked with a flat chemical pattern for all the major components in the core region. Progressively younger grains show steeper gradients in their cores. Steep compositional gradients in garnet cores are, however, rarely reported. We suggest that the typical bell-shaped Mn-curves, which are frequently observed in greenschist to amphibolite facies rocks, result from diffusional relaxation of steep compositional gradients in younger garnet. It should be noticed that this effect is only relevant for sections that crosscut the core of a garnet crystal. Sections, which do not intersect the core, will always produce bell-shaped Mn-gradients.

Moreover, it could be hypothesised that in the case of substantial reaction overstepping, the rate of garnet nucleation may be high already for the first stages in the nucleation interval. In this case, the number of comparatively large garnet grains with a flat chemical gradient in their cores will increase.

\section{Conclusions}

With the development of the software program THERIA_G, earlier work to simulate the formation of compositional profiles in garnet (e.g. Cygan and Lasaga 1982; Loomis 1982; Spear 1988; Spear et al. 1991a; Florence and Spear 1991) is extended to garnet populations. Garnet growth can now be modelled based on the well-founded concepts of equilibrium thermodynamics in complex chemical systems and multicomponent diffusional transport in simple geometries. Based on the assumption that the radial growth rate is similar for all garnet porphyroblasts at a given point in time any predefined garnet CSD can be produced. This offers the opportunity to compare garnet chemistries as well as garnet CSD's that are simulated for predefined conditions with field observations.

Garnet growth simulation with THERIA_G clearly demonstrates that the chemical zoning of garnet porphyroblasts may be influenced by chemical fractionation between matrix and garnet during growth, intracrystalline diffusion in garnet and the nucleation history. In particular, it is shown that the sensitivity of garnet growth zoning to modification by intracrystalline diffusion is different for garnet crystals that nucleated at different stages of the nucleation history. Whereas early nucleated garnet individuals tend to have relatively flat chemical-zoning patterns in their cores, garnet crystals that nucleated late may have sharp compositional gradients in their growth zoning, which are prone to modification through intracrystalline diffusion.

Finally, the software program THERIA_G is suggested as a powerful tool for unravelling the metamorphic history of garnet-bearing rocks from the investigation of garnet chemical zoning. Furthermore, it may allow for testing models for the kinetics of garnet nucleation and growth.

Acknowledgments The current study was strongly inspired by the CUSO short course on "Diffusion in geological materials", held in 2005 at Basel University. In addition, the study benefited from discussions with M. Grote, L. Keller, T. Heijboer and R. Dohmen. The scientific reviews of S. Chakraborty and F. Spear and the editorial work of J. Hoefs are gratefully acknowledged.

\section{References}

Atherton MP (1968) The variation in garnet, biotite, and chlorite composition in medium grade pelitic rocks from the Dalradian, Scotland, with particular reference to the zonation in garnet. Contrib Mineral Petrol 18:347-361

Berman RG (1988) Internally-consistant thermodynamic data for minerals in the system $\mathrm{Na}_{2} \mathrm{O}-\mathrm{K}_{2} \mathrm{O}-\mathrm{CaO}-\mathrm{FeO}-\mathrm{Fe}_{2} \mathrm{O}_{3}-\mathrm{Al}_{2} \mathrm{O}_{3}-$ $\mathrm{SiO}_{2}-\mathrm{TiO}_{2}-\mathrm{H}_{2} \mathrm{O}-\mathrm{CO}_{2}$. J Petrol 29:445-552

Carlson WD (1989) The significance of intergranular diffusion to the mechanism and kinetics of porphyroblast crystallization. Contrib Miner Petrol 103:1-24

Carlson WD (1991) Competitive diffusion-controlled growth of porphyroblasts. Mineral Mag 55:317-330

Cashman KV, Ferry JM (1988) Crystal size distribution (CSD) in rocks and the kinetics and dynamics of crystallization. III. Metamorphic crystallization. Contrib Mineral Petrol 99:401-415

Chakraborty S, Ganguly J (1992) Cation diffusion in aluminosilicate garnets: experimental determination in spessartine-almandine diffusion couples, evaluation of effective binary, diffusion coefficients, and applications. Contrib Mineral Petrol 111:74-86

Chernoff CB, Carlson WD (1997) Disequilibrium for Ca during growth of pelitic garnet. J Metamorph Geol 15:421-438

Christian JW (1975) The theory of transformations in metals and alloys: Part 1-equilibrium and general kinetic theory. Pergamon, Oxford

Crank J (1975) The Mathematics of diffusion. Clarendon Press, Oxford

Crank J, Nicolson P (1947) A practical method for numerical evaluation of solutions of partial differential equations of the heat-conduction type. Proc Camb Philos Soc 43:50-67

Cygan RT, Lasaga AC (1982) Crystal growth and formation of chemical zoning in garnets. Contrib Mineral Petrol 79:187-200

de Capitani C (1994) Gleichgewichts-Phasendiagramme: Theorie und Software. Berichte der Deutschen Mineralogischen Gesellschaft, Beiheft zum. Eur J Mineral 6:48

de Capitani C, Brown TH (1987) The computation of chemical equilibrium in complex systems containing non-ideal solutions. Geochim et Cosmochim Acta 51:2639-2652

Evans G, Blackledge J, Yardley P (1999) Numerical methods for partial differential equations. Springer undergraduate mathematics series. Springer, London 
Florence FP, Spear FS (1991) Effects of diffusional modification of garnet growth zoning on $P-T$ path calculations. Contrib Mineral Petrol 107:487-500

Florence FP, Spear FS (1995) Intergranular diffusion kinetics of Fe and $\mathrm{Mg}$ during retrograde metamorphism of a pelitic gneiss from the Adirondack Mountains. Earth Planet Sci Lett 134:329-340

Gaidies F, de Capitani C, Abart R, Schuster R (2007) Prograde garnet growth along complex $P-T-t$ paths: results from numerical experiments on polyphase garnet from the Wölz Complex (Austroalpine basement). Contrib Mineral Petrol. doi: 10.1007/s00410-007-0264-y

Hauzenberger CA, Robl J, Stuwe K (2005) Garnet zoning in high pressure granulite-facies metapelites, Mozambique belt, SEKenya: constraints on the cooling history. Eur J Mineral 17:4355

Holland TJB, Powell R (1998) An internally consistent thermodynamic data set for phases of petrological interest. J Metamorph Geol 16:309-343

Hollister LS (1966) Garnet zoning: an interpretation based on the Rayleigh fractionation model. Science 154:1647-1651

Keller LM, Abart R, Wirth R, Schmid DW, Kunze K (2006) Enhanced mass transfer through short-circuit diffusion: growth of garnet reaction rims at eclogite facies conditions. Am Mineral 91:1024-1038

Keller LM, Hauzenberger CA, Abart R (2007) Diffusion along interphase boundaries and its effect on retrograde zoning patterns of metamorphic minerals. Contrib Mineral Petrol. 154:205-216

Kretz R (1966) Grain size distribution for certain metamorphic minerals in relation to nucleation and growth. J Geol 75:147-173

Kretz R (1974) Some models for the rate of crystallization of garnet in metamorphic rocks. Lithos 7:123-131

Kretz R (1993) A garnet population in Yellowknife schist, Canada. J Metamorph Geol 11:101-120

Lasaga AC (1979) Multicomponent exchange and diffusion in silicates. Geochim et Cosmochim Acta 43:455-469

Loomis TP (1982) Numerical simulation of the disequilibrium growth of garnet in chlorite-bearing aluminous pelitic rocks. Can Mineral 20:411-423

Loomis TP (1986) Metamorphism of metapelites-calculations of equilibrium assemblages and numerical simulations of the crystallization of garnet. J Metamorph Geol 4:201-229
Loomis TP, Nimick FB (1982) Equilibrium in Mn-Fe-Mg aluminous pelitic compositions and the equilibrium growth of garnet. Can Mineral 20:393-410

Loomis TP, Ganguly J, Elphick SC (1985) Experimental determinations of cation diffusitivities in aluminosilicate garnets. II Multicomponent simulation and tracer diffusion coefficients. Contrib Mineral Petrol 90:45-51

Newton RC, Charlu TV, Kleppa OJ (1980) Thermochemistry of the high structural state plagioclases. Geochim et Cosmochim Acta 44:933-941

Onsager L (1945) Theories and problems of liquid diffusion. Annals of the New York Academy of Sciences 46:241-265

Powell R, Holland TJB (1999) Relating formulations of the thermodynamics of mineral solid solutions: activity modeling of pyroxenes, amphiboles, and micas. Am Mineral 84:1-14

Shaw DM (1956) Geochemistry of pelitic rocks. Part III: major elements and general geochemistry. Geol Soc Am Bull 67:919934

Spear FS (1988) Metamorphic fractional crystallization and internal metasomatism by diffusional homogenization of zoned garnets. Contrib Mineral Petrol 99:507-517

Spear FS (1993) Metamorphic phase equilibria and pressuretemperature-time paths. Mineralogical society of America monograph. Mineralogical Society of America, Washington, DC

Spear FS, Daniel CG (1998) Three-dimensional imaging of garnet porphyroblast sizes and chemical zoning: nucleation and growth history in the garnet zone. Geol Mater Res 1:1-44

Spear FS, Daniel CG (2001) Diffusion control of garnet growth, Harpswell Neck, Maine, USA. J Metamorph Geol 19:179-195

Spear FS, Florence FP (1992) Thermobarometry in granulites: pitfalls and new approaches. Precambrian Res 55:209-241

Spear FS, Kohn MJ, Florence FP, Menard T (1991a) A model for garnet and plagioclase growth in pelitic schists: implications for thermobarometry and $P-T$ path determinations. J Metamorph Geol 8:683-696

Spear FS, Peacock SM, Kohn MJ, Florence FP, Menard T (1991b) Computer programs for petrologic $P-T-t$ path calculations. Am Mineral 76:2009-2012

Zeh A (2006) Calculation of garnet fractionation in metamorphic rocks, with application to a flat-top, Y-rich garnet population from the Ruhla Crystalline Complex, Central Germany. J Petrol 47:2335-2356 